\title{
Trypanosoma vivax causa lesões no encéfalo mesmo na ausência de sinais neurológicos
}

Paulo Henrique Sampaio ${ }^{[]^{*}}$, Kayo José Garcia de Almeida Castilho Neto ${ }^{[a]}$, Otavio Luiz Fidelis Junior ${ }^{[a]}$, Rosangela Zacarias Machado ${ }^{[a]}$, Marcos Rogério André[e], Rosimeri de Oliveira Vasconcelos ${ }^{[a]}$, Antonio Carlos Alessi[a], Fabiano Antonio Cadioli[a,b]

\footnotetext{
[a] Faculdade de Ciências Agrárias e Veterinárias, Universidade Estadual Paulista (UNESP), Jaboticabal, SP, Brasil

${ }^{[b]}$ Faculdade de Medicina Veterinária, Universidade Estadual Paulista (UNESP), Araçatuba, SP, Brasil
}

*Autor correspondente

e-mail: paulohsampa@yahoo.com.br

\section{Resumo}

O Trypanosoma vivax causa doença em ruminantes na África, América Central e América do Sul. 0 parasita tem sido incriminado como causador de alterações neurológicas em ruminantes. Este estudo foi aprovado pela Comissão de Ética no uso de animais da FCAV/UNESP-Jaboticabal, com os processos números 023783/14 e 02080/2010. Foram utilizados três grupos de animais sendo o grupo C ( 2 caprinos Saanen) (tratados com diaceturato de diminazene) e o grupo E (3 bovinos Girolandos) (não tratados), ambos experimentalmente infectados por T. vivax. E o grupo $\mathrm{N}$ ( 2 bovinos girolandos) oriundos de um surto de T. vivax, também na fase crônica. A eutanásia dos animais foi conduzida seguindo-se protocolo adequado à espécie e procedeu-se a análise histológica. Nos animais dos grupos C e E não foram observados sinais clínicos neurológicos, exceto E3, apresentando leve incoordenação motora. Dois bovinos do grupo $\mathrm{N}$ apresentaram ataxia discreta, dismetria e depressão, sendo que N1 evoluiu para ataxia grave e decúbito permanente. Macroscopicamente, os encéfalos de todos os animais não apresentaram alterações, porém na análise microscópica do grupo C observou-se discreto edema intersticial, hemorragia focal e congestão difusa moderada. Notou-se também gliose difusa moderada no córtex cerebral. No hipocampo detectou-se edema intersticial e focos de necrose de neurônios. Nos animais do grupo E observou-se aumento de celularidade ao redor de neurônios, neuroniofagia, focos de cromatólise neuronal, gliose, manguitos perivasculares focais discretos, compostos por linfócitos e focos de hemorragia. Nos animais do grupo $\mathrm{N}$ detectou-se gliose, edema intersticial, neuroniofagia, discretas áreas focais com astrócitos reativos e outras apresentando manguitos perivasculares com infiltrado inflamatório composto por linfócitos. No cerebelo observou-se focos de tumefação axonal e hemorragia focal discretos. Alterações estruturais e celulares em SNC de ruminantes infectados por T. vivax já foram descritas na literatura e confirmadas no presente estudo. Os animais do grupo $\mathrm{N}$ mostraram gliose mais intensa, com presença de 
astrócitos hipertrofiados, sugerindo que reatividade de maior magnitude destas células esteja relacionada à maior intensidade das lesões na fase crônica da infecção. No presente trabalho observou-se reatividade microglial e necrose neuronal nos animais. A ativação microglial poderia estar relacionada à maior proporção de neurônios necróticos, detectada nos bovinos na fase crônica da infecção, mas não nos caprinos (fase aguda). No presente trabalho foi observado edema intersticial nos caprinos e bovinos estudados. Provavelmente, o parasita desencadeia o edema por quebra da barreira hematoencefálica (BHE) e este fato pode agravar as lesões teciduais no SNC. As lesões no encéfalo dos animais do grupo C sugerem que T. vivax atravessa a BHE em um estágio precoce da doença, mesmo sem a manifestação de sinais. A ocorrência de sinais neurológicos está relacionada ao agravamento das lesões encefálicas, como observado nos animais do grupo $\mathrm{N}$. 